http://ojs.stikes-muhammadiyahku.ac.id/index.php/herbapharma

\title{
UJI EFEKTIVITAS AIR PERASAN JERUK NIPIS (Citrus aurantifolia (Christm.) Swingle)DALAM MENGHAMBAT PERTUMBUHAN JAMUR Candida albicans
}

\section{Sukmawati ${ }^{1}$, Toto Santoso ${ }^{2}$, Alda Miranti $^{3}$}

\author{
${ }^{1,2,3}$ STIKes Muhammadiyah Kuningan \\ *E-mail : rav3nz46@gmail.com
}

\begin{abstract}
ABSTRAK
Masalah yang sering terjadi di masyarakat adalah penyakit kandidiasis yang disebabkan oleh beberapa jamur salah satunya Candida albicans. Jeruk nipis (Citrus aurantifolia (Christm.) Swingle) merupakan tanaman obat yang tumbuh subur di negara Indonesia. Salah satu kandungan utama dari jeruk nipis (Citrus aurantifolia (Christm.) Swingle) adalah flavonoid yang memberikan berbagai macam aktivitas farmakologi sebagai antifungi, antibakteri dan antikanker. Penelitian ini bertujuan untuk mengetahui efektivitas air perasan jeruk nipis, (Citrus aurantifolia (Christm.) Swingle) dalam menghambat pertumbuhan jamur Candida albicans. Metode yang digunakan dalam penelitian ini adalah dengan cara dilusi padat yaitu dengan cara menanam biakan suspensi jamur Candida albican sebanyak $1 \mathrm{ml}$ yang telah di sesuaikan kekeruhannya dengan larutan standar Mc Farland 0.5 pada media SDA (Sabouraud Agar Dexrose) dengan penambahan air perasan jeruk nipis sebanyak $2 \mathrm{ml}$ dengan konsentrasi $125 \%, 150 \%, 175 \%$ dan $200 \%$. Di inkubasi selama $2-3$ hari pada $37^{\circ} \mathrm{C}$, dan diamati pertumbuhannya. Hasil dari pengamatan selama tiga hari menunjukan bahwa air perasan jeruk nipis tidak efektif dalam menghambat pertumbuhan jamur Candida albicans, meskipun pada konsentrasi $175 \%$ dan $200 \%$ pertumbuhan jamur pada hari pertama sangat sedikit, tetapi pada hari kedua dan ketiga masih ada perluasan pertumbuhan jamur Candida albicans.
\end{abstract}

Kata Kunci: Antifungi, Candida albicans, Jeruk nipis

\begin{abstract}
The problem that often occurs in the community is candidiasis caused by several fungi, one of which is Candida albicans. Lime (Citrus aurantifolia (Christm.) Swingle) is a medicinal plant that thrives in Indonesia. One of the main ingredients of lime (Citrus aurantifolia (Christm.) Swingle) is flavonoid which provides various kinds of pharmacological activities as antifungal, antibacterial and anticancer. This study aims to determine the effectiveness of lime juice (Citrus aurantifolia (Christm.) Swingle) in inhibiting the growth of the fungus Candida albicans. The method used in this study is by solid dilution, namely by planting a suspension of Candida albican fungus as much as $1 \mathrm{ml}$ which has been adjusted for turbidity with standard Mc Farland 0.5 solution on SDA media (Sabouraud Agar Dexrose) with the addition of 2 lime juice. $\mathrm{ml}$ with concentrations of $125 \%, 150 \%, 175 \%$ and $200 \%$. Incubated for 2-3 days at $37^{\circ} \mathrm{C}$, and observed growth. The results of observations for three days showed that lime juice was not effective in inhibiting the growth of Candida albicans fungus, although at concentrations of $175 \%$ and $200 \%$ the growth of the fungus on the first day was very little, but on the second and third days there was still expansion of the growth of Candida albicans.
\end{abstract}

Keywords: Antifungal, Candida albicans, Lime 


\section{PENDAHULUAN}

Masalah yang sering terjadi di masyarakat adalah penyakit kandidiasis yang disebabkan oleh beberapa jamur salah satunya Candida albicans. Hampir disetiap tubuh kita mengandung jamur Candida albicans termasuk di daerah mukosa mulut, kulit, saluran cerna, dan alat kelamin, namun adanya jamur ini tidak menimbulkan keluhan yang berarti. Candida albicans merupakan flora normal dalam tubuh manusia, namun bila dalam jumlah yang berlebih akan menjadi patogen (oportunistik). Jamur Candida albicans dapat tumbuh dengan baik di tempat yang lembab (Maimunah et al,. 2018).

Kandidiasis adalah penyakit jamur, yang bersifat akut atau subakut disebabkan oleh genus Candida, biasanya oleh spesies Candida albicans dan dapat mengenai mulut, vagina, kulit, kuku, bronki, atau paru, kadang-kadang dapat menyebabkan septikemia, endokarditis, atau meningitis (Rahayu Sawitri, 2019).

Jeruk nipis (Citrus aurantifolia (Christm.)Swingle) adalah salah satu tanaman obat yang tumbuh subur di negara Indonesia.Salah satu kandungan utama dari jeruk nipis (Citrus aurantifolia (Christm.)Swingle) adalah flavonoid yang memberikan berbagai macam aktivitas farmakologi.Aktivitas farmakologi jeruk nipis (Citrus aurantifolia (Christm.) Swingle) diantaranya adalah antibakteri, antifungal, antioksidan, antikanker, sebagai pemutih gigi, larvasida nyamuk aedes aegypti, antikolesterol (Prastiwi et al,. 2017)

Berdasarkan hasil penelitian yang telah dilakukan oleh peneliti sebelumnya bahwa perasan air buah jeruk nipis (Citrus aurantifolia (Christm.) Swingle) pada konsentrasi 20\%, 40\%, 60\%, 80\% dan $100 \%$ tidak mampu dalam menghambat pertumbuhan jamur Candida albicans(Maimunah et al,. 2018). Oleh karena itu peneliti tertarik untuk meneliti kembali apakah air jeruk nipis (Citrus aurantifolia (Christm.) Swingle) mampu menghambat pertumbuhan jamur Candida albicans, dengan konsentrasi diatas $100 \%$ dengan cara dilusi padat

\section{BAHAN DAN METODE}

\section{Bahan dan Alat}

Bahan yang digunakan yaitu Media SDA (Sabouraud Dextrose Agar), Air Perasan Jeruk Nipis (Citrus aurantifolia (Christm.) Swingle), Isolat Jamur Candida albicans, Aquadest steril, $\mathrm{NaCl}$ 0.9\%, $\mathrm{BaCl} 1 \%, \mathrm{H}_{2} \mathrm{SO}_{4} 1 \%$.

Cawan petri (ANUMBRA), Beaker glass (PYREX), Erlenmeyer (PYREX), Jarum ose, Pipet tetes, Pipet Volume, Tabung reaksi (PYREX), Rak tabung reaksi, Alumunium foil, Timbangan analitik (NEW TECH), Kapas, Batang pengaduk, Korek api, Lampu spiritus, Lap, Alat pemeras jeruk, Kertas saring, Autoklaf (HIRAYAMA), Inkubator (MEMMERT)

\section{Jenis Penelitian}

Metode yang digunakan dalam penelitian ini bersifat eksperimental, karena sampel dibuat dengan konsentrasi yang bervariasi.Sampel atau subjek penelitian yang digunakan dalam penelitian ini berupa air perasan jeruk nipis (Citrus aurantifolia (Christm.) Swingle) sebanyak $2 \mathrm{ml}$ dengan konsetrasi $125 \%, 150 \%, 175 \%$, dan $200 \%$. Setiap variasi konsentrasi diujikan pada objek penelitian yaitu suspensi jamur Candida albicans yang telah disetarakan kekeruhannya dengan kekeruhan standar Mc Farland 0.5. Proses identifikasi penelitian ini meliputi penanaman jamur isolat murni pada media SDA (Sabouraud Agar Dextrose) dengan metode cawan tuang.

\section{Lokasi dan Waktu Penelitian}

Penelitian ini mulai dilaksanakan bulan Desember 2020, dari awal perencanaan (penyusunan proposal) sampai dengan penyusunan laporan akhir dan pengumpulan data yang akan dilakukan pada bulan April 2021.

Tempat pelaksanaan penelitian dilakukan di Laboratorium Mikrobiologi Muhammadiyah Kuningan. 


\section{PROSEDUR PENELITIAN}

Penelitian ini di lakukan secara steril dan aseptis.Sterilisasi alat-alat yang akan digunakan dengan autoklaf selama kurang lebih 15 menit pada suhu $121^{\circ} \mathrm{C}$.

\section{Peremajaan Jamur Candida Albicans}

Peremajaan jamur Candda albicans, dilakukan dengan cara menanam isolat murni jamur Candida albicans pada media SDA, kemudian di inkubasi pada suhu $37^{\circ} \mathrm{C}$, selama 24 jam.

\section{Pembuatan Konsentrasi Air Perasan Jeruk Nipis}

Pembuatan konsentrasi air persasan jeruk nipis yang diguanakan dibuat sebanyak $2 \mathrm{ml}$ dengan perbandingan $\mathrm{v} / \mathrm{v}$.

Tabel 1. Tabel Pembuatan Konsentrasi Air Perasan Jeruk Nipis

\begin{tabular}{cccc}
\hline & Air perasan Jeruk Nipis & Aquadest & Keterangan konsentrasi \\
\hline A & $1,25 \mathrm{ml}$ & $0,75 \mathrm{ml}$ & $125 \%$ \\
$B$ & $1,50 \mathrm{ml}$ & $0,50 \mathrm{ml}$ & $150 \%$ \\
C & $1,75 \mathrm{ml}$ & $0,25 \mathrm{ml}$ & $175 \%$ \\
D & $2,0 \mathrm{ml}$ & - & $200 \%$ \\
\hline
\end{tabular}

\section{Pembuatan Media SDA (Sabouraud Dextrose Agar)}

Timbang media SDA sebanyak 6,5 gram. kemudian masukkan ke dalam beaker glass, dilarutkan dengan $100 \mathrm{ml}$ aquades, lalu panaskan diaduk sampai homogen dan mendidih selama kurang lebih 15 menit. Masukan media kedalam erlenmeyer lalu tutup menggunakan kapas dan alumunium steril, kemudian sterilisasi menggunakan autoklaf pada suhu $121^{\circ} \mathrm{C}$ selama kurang lebih 15 menit.Biarkan dingin dan untuk disimpan.

\section{Pembuatan Larutan Standar Mc Farland 0,5}

Larutan standar Mc Farland 0,5 sebanyak $10 \mathrm{ml}$ dibuat dengan mencampurkan $0,05 \mathrm{ml}$ larutan $\mathrm{BaCl}_{2} 1 \%$ dengan $9,95 \mathrm{ml}$ larutan $\mathrm{H}_{2} \mathrm{SO}_{4} 1 \%$, hingga didapat standart Mc Farland 0,5 dan

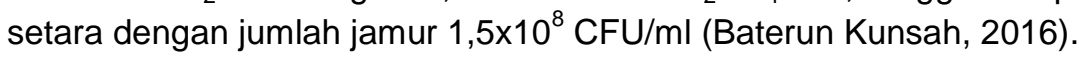

\section{Pembuatan Suspensi Candida albicans}

Mengambil satu ose isolat jamur Candida albicans dimasukkan pada tabung reaksi yang berisi $10 \mathrm{ml}$ $\mathrm{NaCl}$ 0.9\%, kemudian homogenkan.Sesuaikan kekeruhan dengan larutan standar Mc Farland 0,5 secara visual.

\section{Prosedur Pemeriksaan Daya Hambat Pertumbuhan Jamur Candida albicans}

Suspensi jamur Candida albicans yang telah disesuaikan dengan larutan standar Mc. Farland 0.5 sebanyak $1 \mathrm{ml}$ dituang kedalam cawan petri steril, tambahkan air perasan jeruk nipis dengan konsetrasi 125\%, kemudian tambahkan media SDA (Sabouraud Dextrose Agar) cair steril, kemudian diputar membentuk angka 8 hingga homogen. Biarkan media dingin dan memadat, lakukan hal yang sama dengan penambahan air perasan jeruk nipis dengan konsentrasi $150 \%, 175 \%$, dan $200 \%$. Selanjutnya keempat cawan petri dimasukan kedalam inkubator untuk diinkubasi selama hari dengan suhu $37^{\circ} \mathrm{C}$, dan diamati pertumbuhan yang setiap 24 jam. 


\section{Analisis Data}

Analisis hasil uji anti jamur dilakukan dengan cara melihat pertumbuhan koloni jamur pada media SDA (Sabouraud Dextrse Agar) yang sudah ditambahkan air perasan jeruk nipis dengan konsentrasi yang berbeda- beda dan suspensi jamur Candida albicans.

\section{HASIL DAN PEMBAHASAN}

Hasil dari penelitian Uji Efektivitas Air Perasan Jeruk Nipis (Citrus aurantifolia (Christm.) Swingle) dalam menghambat pertumbuhan jamur Candida albicans diketahui sebagai berikut :
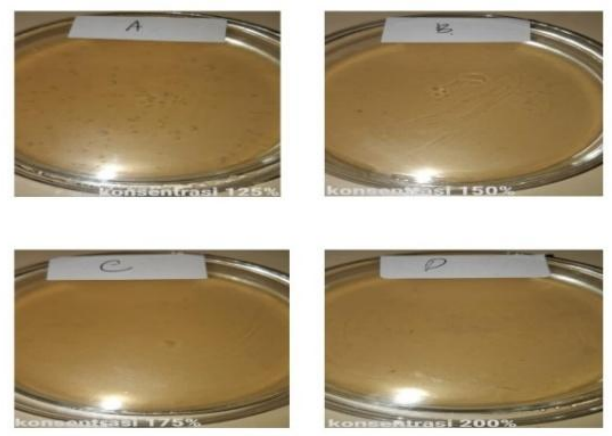

Gambar 1. Gambar Hasil Pengamatan pada hari Pertama
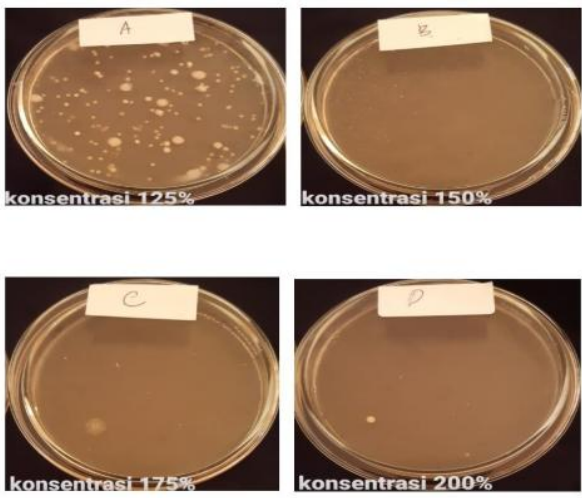

Gambar 2. Gambar Hasil Pengamatan pada hari Kedua
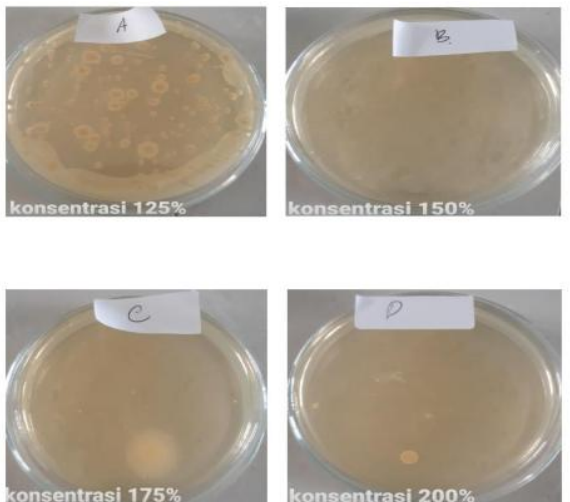

Gambar 3. Gambar Hasil Pengamatan pada hari Ketiga 


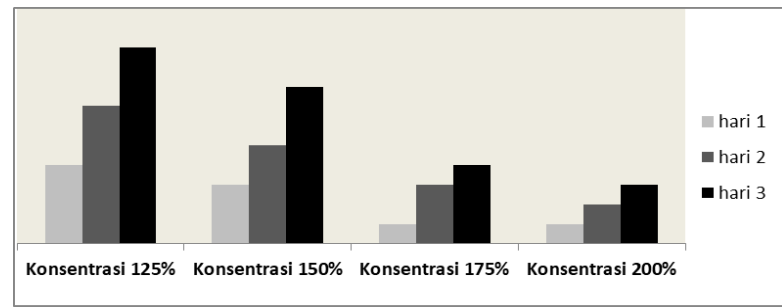

Gambar 4. Grafik pertumbuhan jamur Candida albicans selama 3 hari.

Menurut peneliti air perasan buah jeruk nipis (Citrus aurantifolia (Christm.) Swingle) sebanyak $2 \mathrm{ml}$ dengan masing- masing konsentrasi 125\%, 150\%, 175\%, dan 200\% telah diujikan dengan $1 \mathrm{ml}$ suspensi jamur Candida albicans yang, ditanam pada media SDA dan diinkubasi selama 3 hari dengan suhu $37^{\circ} \mathrm{C}$. Berdasarkan pengamatan selama tiga hari pada masing-masing konsetrasi, jamur Candida albicans masih tetap tumbuh, meskipun pada konsentrasi $175 \%$ dan $200 \%$ pertumbuhan jamur pada hari pertama sangat sedikit, tetapi pada hari kedua dan ketiga masih ada perluasan pertumbuhan jamur Candida albicans.

Salah satu faktor yang sangat mempengaruhi aktivitas antimikroba adalah takaran inokulum, karena semakin besar inokulum bakteri maka kesensitifan organisme akan semakin rendah. Perbedaan konsentrasi disebabkan karena adanya perbedaan senyawa yang terkandung dalam air jeruk nipis (Razak et al., 2013)

Konsentrasi air perasan jeruk nipis yang memungkinkan terjadinya interaksi optimal akan memberikan aktivitas optimal pula, tidak bergantung pada besar atau kecilnya konsentrasi air perasan tersebut. Semakin tinggi konsentrasi ekstrak maka semakin luas zona hambat berarti menunjukkan semakin tinggi efektivitas untuk membunuh atau menghambat pertumbuhan jamur (Nurhasanah et al., 2017).

Selain perbedaan senyawa yang terkandung di dalam air perasan buah jeruk nipis, pertumbuhan jamur tersebut dipengaruhi oleh perbedaan jumlah mikroba yang ditumbuhkan pada media, karena dalam $1 \mathrm{~mL}$ suspensi jumlah sel jamur belum tentu sama (Yuni, 2020).

\section{SIMPULAN}

Berdasarkan hasil penelitian dan pembahasan diatas dapat disimpulkan bahwa air perasan jeruk nipis tidakmampu dalam menghambat pertumbuhan jamur Candida albicans. Air perasan jeruk nipis sebanyak $2 \mathrm{ml}$ dengan masing- masing konsentrasi $125 \%, 150 \%, 175 \%$, dan $200 \%$ telah diujikan dengan $1 \mathrm{ml}$ suspensi jamur Candida albicans yang ditanam pada media SDA dan diinkubasi selama 3 hari dengan suhu $37^{\circ} \mathrm{C}$. Hasil pengamatan selama tiga hari pada masing-masing konsetrasi, jamur masih tetap tumbuh, meskipun pada konsentrasi $175 \%$ dan $200 \%$ pertumbuhan jamur pada hari pertama sangat sedikit, tetapi pada hari kedua dan ketiga masih ada perluasan pertumbuhan jamur Candida albicans.

\section{REFERENSI}

Maimunah, E., F, A. and Rohhani, S. (2018) 'UJI EFEKTIFITAS AIR BUAH JERUK NIPIS (Citrus aurantifolia) DALAM MENGHAMBAT Candida albicans', (STIKes ICMe Jombang). Diploma thesis, STIKES Insan Cendekia Medika Jombang.

Nurhasanah, N., Andrini, F. and Hamidy, Y. (2017) 'Aktivitas Antifungi Air Perasan Bawang Merah (Allium ascalonicum $\quad$ L.) Terhadap Candida albicans Secara In Vitro', Jurnal IImu Kedokteran, 9(2), pp. 71-77.

Penelitian, L., Pengabdian, D. A. N. and Surabaya, U. M. (2016) “" Efektifitas Variasi Perasaan 
Jeruk Nipis (Citrus aurantifolia) Terhadap Pertumbuhan Candida albicans Secara In Vitro Efektifitas Variasi Perasaan Jeruk Nipis (Citrus aurantifolia) Terhadap Pertumbuhan Candida albicans Secara In Vitro .

Prastiwi, S. S. and Ferdiansyah, F. (2017) 'REVIEW ARTIKEL: KANDUNGAN DAN AKTIVITAS FARMAKOLOGI JERUK NIPIS (Citrus aurantifolia s.)', Farmaka.

RAHAYU SAWITRI, D. (2019) GAMBARAN Candida albicans PADA AIR KOLAM RENANG DI KABUPATEN PRINGSEWU TAHUN 2019. Poltekkes tanjungkarang.

Razak, A., Djamal, A. and Revilla, G. (2013) 'Uji Daya Hambat Air Perasan Buah Jeruk Nipis (Citrus aurantifolia s.) Terhadap Pertumbuhan Bakteri Staphylococcus Aureus Secara In Vitro', Jurnal Kesehatan Andalas, 2(1), p. 05. doi: 10.25077/jka.v2i1.54.

YUNI, A. (2020) FORMULASI DAN UJI DAYA HAMBAT SPRAY HAND SANITIZER DARI AIR PERASAN JERUK NIPIS (Citrus aurantiifolia (Christm.) Swingle) TERHADAP Staphylococcus aureus. Universitas perintis Indonesia. 